\title{
(Re)estruturação urbana de Teresina (PI): uma análise de suas dinâmicas recentes
}

\author{
Paulo Henrique de carvalho Bueno \\ Antônia Jesuíta De Lima
}

(Re)estruturação urbana de Teresina (PI): uma análise de suas dinâmicas recentes

Resumo: Objetiva-se desenvolver uma discussão acerca do processo de (re)estruturação urbana e suas dinâmicas recentes em Teresina (PI), as quais fomentam a diferenciação socioespacial por região ou zona da cidade. No âmbito dessas diferenças, tem-se que a zona Leste se constitui, em termos de complementariedade e concorrência com o Centro, como a mais equipada com atividades comerciais e de serviços, espaços de lazer, construções habitacionais de maiores valores econômicos, o que promove uma fragmentação e diferenciação socioespacial na capital, assim como no bojo da própria região. As análises dessas constatações são fruto de uma revisão bibliográfica e de dados empíricos acerca de atividades comerciais e de serviços que se territorializam no espaço urbano da capital piauiense. Complementa-se, ainda, o estudo, com um debate das novas formas de habitar em Teresina, representados pelos processos de verticalização e expansão dos condomínios horizontais.

Palavras-Chave: Produção Espacial. (Re)estruturação Urbana. Espaço Urbano de Teresina.

\section{Urban restructuring of Teresina (PI): an analysis of its recent dynamics}

Abstract: The object is to discuss about the urban (re)structuring process and its recent dynamics in Teresina (PI), which stimulate the socio-spatial differentiation by region or district of the city. In the scope of this differentiation, the least region is constituted, in terms of noncomplementarity and competition with the downtown region, as the most equipped with commercial and services activities, entertainment, inhabitations of greater economic value, what promotes a socio-spatial fragmentation and differentiation in the capital, as well as in the region itself. The analyses of these findings are the result of a literature review and of empiric data about the commercial and service activities that territorialize in the urban space of the capital of the State of Piaui. The study is also complemented by a debate of the new form of inhabit in Teresina, represented by the process of verticalisation and expansion of the horizontal condominiums.

Keywords: Spacial Production. Urban (Re)structuring. Teresina (PI).

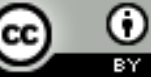

Esta obra foi licenciada sob uma Licença Creative Commons - Atribuição 3.0 Não Adaptada. 


\section{Introdução}

O crescimento das cidades processam produções espaciais que se refletem em sua (re)estruturação urbana, entendida como mudanças nas formas e conteúdos imprimidas pela sociedade em seu cotidiano. Nesse sentido, são perceptíveis, em especial nas urbes médias e grandes, novos movimentos de territorialização de atividades comerciais e de serviços em determinados espaços citadinos, assim como a expansão espacial da ocupação e uso do solo urbano, como ações que dinamizam e (re)configuram o tecido citadino. É a partir dessa percepção que se busca desenvolver uma discussão dos elementos presentes em Teresina (PI) que evidenciam seu processo de (re)estruturação urbana, o qual é fruto de ações de agentes privados e do estado. As análises dessas constatações são fruto de uma revisão bibliográfica - estudos sobre produção do espaço urbano e pesquisas que buscam compreender a dinâmica da capital piauiense sob diversos aspectos (construções habitacionais, ocupações do solo urbano, políticas e legislações urbanas, mobilidade urbana e distribuição das atividades comerciais e de serviços) - e de dados empíricos acerca de atividades comerciais e de serviços que se territorializam no espaço urbano da capital piauiense. Complementa-se, ainda, o estudo, com um debate acerca das novas formas de habitar em Teresina, representados pelos processos de verticalização e expansão dos condomínios horizontais.

Argumenta-se que as transformações socioespaciais ocorridas em Teresina, principalmente a partir de 1950, permitem discutir a diferenciação socioespacial por região ou zona da cidade. No âmbito dessas diferenças, tem-se que a zona Leste se constitui, em termos de complementariedade e concorrência com o Centro, como a mais equipada com atividades comerciais e de serviços, espaços de lazer, construções habitacionais de maiores valores econômicos, o que promove uma fragmentação e diferenciação socioespacial na capital, assim como no bojo da própria região.

\section{Produção do espaço e (re)estruturação urbana: uma breve reflexão}

As discussões acerca do processo de urbanização e da produção da cidade por seus agentes produtores, os quais, segundo Corrêa (1989), são o Estado, os proprietários dos meios de produção, os promotores imobiliários, os proprietários fundiários e os grupos socialmente excluídos, remete a reflexões sobre a constituição da (re)estruturação urbana e da cidade. Daí que esse fenômeno requer que se considere os processos de (re)construção entre esses elementos como acumulação de tempos, sublinhando a urbanização e suas determinações (CORRÊA, 2006; SANTOS, 2008c; 2008d;). Assim, analisar a urbanização requer compreendê-la como um processo, como um movimento espaço-temporal complexo e dinâmico, permitindo que se compreendam as múltiplas conexões entre espaço e tempo não somente do ponto de vista da sucessão e sincronia entre objetos e ações, mas também na perspectiva dos descompassos, conflitos e inflexões que marcam esse movimento articulador dessas duas dimensões da existência - espaço e tempo (SPÓSITO, 2011; 2010; 2004; 2000).

A ideia de urbanização como movimento, o qual se caracteriza como um modo de vida, se constitui em um fenômeno que promove transformações territoriais significativas, dentre elas a de (re)estruturação urbana e da cidade (RODRIGUES, 2013; SPÓSITO, 2004; 2002; 2001). Nessa senda, a reestruturação urbana corresponde às 
dinâmicas e processos referentes aos espaços regionais, que ocorrem na rede urbana de uma dada espacialidade. Já a reestruturação das cidades refere-se às dinâmicas e processos presentes na escala intraurbana. Destarte, articulam-se duas escalas geográficas, distintas, mas interligadas, a interurbana e a intraurbana, as quais possuem diversas determinações entre si estabelecidas (SPÓSITO, 2007; CORRÊA, 2006).

Assim, a noção de (re)estruturação permite explicações das mudanças na morfologia urbana, espaço em que o fenômeno necessita de uma compreensão que passe, indubitavelmente, pela análise das novas lógicas locacionais e pelo sistema de mercado, que possibilita o acesso e as diferenças na apropriação de determinada porção da cidade pelos diversos segmentos sociais, o que traz à tona as práticas segregacionistas que permeiam o espaço urbano (MONTESSORO, 2006), ou seja, fazse necessário compreender as (re)funcionalizações do tecido citadino com vistas a se adequar as novas formas de uso, produção, organização e apropriação do solo urbano, uma vez que a cidade se constitui como uma mercadoria em que o consumo dos espaços evidencia os conflitos entre os agentes produtores e suas lógicas (WHITACKER, 2003; VILLAÇA, 2001; CORRÊA, 1989).

Compreende-se, pois, que o espaço urbano deve ser vislumbrado como produção espacial, histórica e temporal. Assim, para sua a análise, mesmo que em recortes específicos, perpassa a relação entre forma e processo, a qual é tecida a partir das intenções dos agentes produtores do espaço. Ressalte-se ainda que se deve buscar a compreensão da função e estrutura dos espaços pesquisados, uma vez que a funcionalidade especializada e fragmentação socioeconômica é o "[...]que fratura a textura constituída pelas formas pretéritas de produção do território da cidade e de territorialização intraurbana de seus múltiplos papéis" (SPÓSITO, 1996, p. 94). Destarte, o espaço intraurbano é estruturado sob os interesses do consumo, enquanto uma mercadoria, ou seja, o espaço urbano é produzido e consumido por meio das apropriações que determinadas classes socais promovem no seu viver societário (VILLAÇA, 2001).

Nessa direção, a compreensão dos processos que estruturam e reestruturam o urbano parte das relações contraditórias entre a produção do espaço e as forças de reprodução da sociedade, enfim um conjunto de fixos e fluxos dentro de um sistema socioeconômico historicamente construído (SANTOS, 2008a; 2008b). Logo, a análise da dinâmica urbana, encerrada na díade fixo-fluxo (CARLOS, 1992), aponta que a lógica do Estado e a do capital conjugam-se com o desenvolvimento do meio técnico, científico e informacional, tendendo a promover uma fragmentação espacial, expressa em uma diferenciação e especialização dos lugares em nível territorial, com cidades ou frações citadinas voltadas para a produção, o consumo ou a moradia (LIMONAD, 2006). Na verdade, a fragmentação espacial da cidade para a produção, o consumo ou a habitação se efetiva pela diferenciação socioespacial na qual processos e práticas espaciais produzem e reproduzem distintos padrões (CORRÊA, 2007) em que essa diferenciação traduz-se como desigualdade socioespacial (CARLOS, 2007).

Na produção do espaço urbano, os processos espaciais se constituem em ações realizadas pelos diversos agentes produtores que atuam ao longo do tempo e produzem na cidade fenômenos como a centralização de atividades comerciais e de serviços, descentralização e segregação residencial. A ideia de processos espaciais em Corrêa (2007) conduz ao raciocínio de que para se analisar a produção espacial urbana deve-se 
considerar o tempo como uma dimensão indissociável do espaço, em que as ações humanas produzem formas espaciais que revelam a história da realidade urbana, não sendo, portanto, um produto acabado, mas que vai se constituindo ao longo do tempo. Essa constituição é realizada a partir das práticas espaciais, entendidas como "[...] ações espacialmente localizadas, engendradas por agentes sociais concretos, visando a objetivar seus projetos específicos[...], caracterizadas por uma escala temporal limitada" (CORRÊA, 2007, p. 68-69).

As práticas espaciais realizadas de forma sistemática, regular, com uma escala temporal longa transformam-se em processos espaciais (CORRÊA, 2007) e acabam por configurar o espaço urbano como fragmentado e diferenciado socioespacialmente, podendo ser lido na própria paisagem urbana. Assim, para o entendimento dessas diferenças que geram fragmentações, faz-se necessário relacionar essa dinâmica com a estrutura espacial urbana total e com os elementos da totalidade social, analisando como o espaço urbano se constitui um fator de dominação por determinadas classes sociais pela promoção da produção social do espaço e do tempo (VILLAÇA, 2011). É que analisar o espaço urbano, segundo Carlos (1992, p.79), “[...] significa pensar o homem enquanto ser individual e social no seu cotidiano, no seu modo de viver, agir e pensar", pelo que, conforme Corrêa (1989, p.9), o espaço urbano se constitui como "[...] fragmentado e articulado, reflexo e condicionante social, um conjunto de símbolos e campo de lutas. É, assim, a própria sociedade em uma de suas dimensões, aquela mais aparente, materializada nas formas espaciais [...]". Enfim, refletir acerca da produção social do espaço significa que se deve captar o modo histórico e social de produção da forma a partir do entendimento das relações entre os espaços e os constituintes da organização social (economia, política e valores ideológicos), o que possibilita entender o urbano por meio dos processos que o produzem, mantêm e reproduzem esse espaço de habitação (GOTTDIENER, 1997).

$\mathrm{Na}$ discussão da produção espacial urbana, a análise do papel do Estado como um dos agentes (re)produtores do espaço é fundamental, uma vez que atua também na organização espacial da sociedade e dá suporte infraestrutural para a (re)produção socioespacial (CORRÊA, 1989), o que evidencia as materialidades das políticas públicas. A atuação estatal visa, nessa perspectiva, à satisfação básica da população e à criação do alicerce para a (re)produção do capital, uma das determinações estruturais do estado capitalista (OFFE, 1984), admitindo-se que "sua ação é marcada pelos conflitos dos diferentes membros da sociedade de classe, bem como da aliança entre eles" (CORRÊA, 1989, p. 26). Dessa forma, depreende-se que o espaço urbano caracteriza-se pela fluidez espaço-temporal e sua (re)produção decorre das interrelações entre o poder público e os outros agentes produtores do espaço, ou seja, das interpenetrações do público com o privado.

Mas essa fluidez no espaço também advém do desenvolvimento dos meios de transportes e telecomunicações, que provoca(ra)m mudanças existenciais no urbano, alterando características quantitativas e qualitativas dos equipamentos e serviços. Por conseguinte, é a partir da produção do espaço urbano que se busca a compreensão do processo de urbanização nas sociedades, no nível local, no regional ou no nacional. Além disso, a compreensão dessa dinâmica urbana auxilia, por conseguinte, as interpretações da urbe como fragmentada, articulada, conflituosa, portadora de diferenciações socioespaciais e a (re)estruturação urbana e da cidade. Assim, a 
expressão estruturação urbana permite a identificação dos conteúdos inerentes ao processo de urbanização, os quais podem ser interpretados a partir dos sistemas de ações que sustentam a (re)produção do espaço urbano. Já a expressão estruturação da cidade revela as concretizações dos processos de urbanização e materializa os sistemas de objetos, as formas urbanas, ao nível do intraurbano (SANTOS JÚNIOR, 2008).

\subsection{As transformações recentes na estrutura urbana de Teresina}

Fundada em 1852, Teresina foi instalada para ser o centro políticoadministrativo e econômico do estado, fato que contribuiu para que a mesma constituísse uma centralidade frente ao território estadual. Inicialmente, essa função da cidade foi se concretizando timidamente até os fins dos anos de 1940 e teve uma inflexão com a adoção da política federal de integração nacional por vias rodoviárias iniciadas na década de 1950, as quais tomaram vigor maior nas décadas seguintes (1960 e 1970), posto que fizeram a ligação de Teresina com a região Nordeste e o restante do país. Esses elementos conferiram à capital a função de polarizadora em relação ao território estadual que repercutiram no aumento significativo em termos demográficos e econômicos, com efeito, na dinâmica da produção espacial urbana (ABREU, 1983).

Teresina surgiu sob o signo do moderno, uma vez que sua transferência visou desobstruir as limitações de comunicação entre o Piauí e as demais províncias brasileiras, assim como diminuir a dependência econômica em relação ao Maranhão, a qual era resultado, principalmente, do papel comercial exercido pela cidade de Caxias (MA). Destarte, um novo centro de poder, localizado às margens do rio Parnaíba, curso d'água que margeia grande parte do território piauiense, serviria, em um primeiro momento, como via de conexão com o estado e com o Brasil. Foi assim que Teresina foi pensada e edificada para ser a capital do Piaú e desenvolvê-lo por meio da navegação do rio Parnaíba através da criação de um polo comercial propício à emancipação do mercado maranhense (NASCIMENTO, 2011; 2002; LIMA, 2010a; QUEIROZ, 1994).

As funções para as quais Teresina foi fundada para exercer se realizaram lentamente ao longo de um século de existência. No início da segunda metade do século $\mathrm{XX}$, a nova capital já vivenciava mudanças substanciais, espacial e demograficamente, mas seu crescimento, quando comparado ao de outras cidades do estado, caso de Parnaíba e Floriano, era menor (NASCIMENTO, 2011; ABREU, 1983).

A atração populacional exercida por Teresina refletiu-se em sua produção espacial urbana, seja em relação ao crescimento do tecido citadino, seja em relação ao uso e ocupação do solo e espacialização dos estratos sociais. A área central, mais dotada de equipamentos e de infraestrutura urbana quando comparada com a periférica, foi o espaço de habitação das classes sociais com maior poder aquisitivo, enquanto que os mais pobres foram ocupar as franjas urbanas, uma das evidências que o acesso ao solo urbano e suas benfeitorias ficou condicionado à renda de seus habitantes. Assim, os detentores de maiores aquisições monetárias consumiam os serviços públicos de infraestrutura, enquanto os pobres ficavam à margem dessas melhorias.

$\mathrm{Na}$ verdade, até os anos de 1940 a área central da cidade estava plenamente ocupada e a produção espacial urbana expandiu-se, entre os anos de 1940 e 1960, para outras direções (norte e sul). Mas, no início da década de 1970, outra direção é vislumbrada, a leste. Na direção oeste, Teresina limita-se com o município de Timom 
(MA) e tem o rio Parnaíba como divisor natural entre as fronteirais, fato que obstrui seu crescimento a ocidente (LIMA, 2010a; FAÇANHA, 1998; ABREU, 1983) ${ }^{1}$.

A expansão urbana de Teresina passa por uma inflexão a partir de 1950, década em que a capital experimenta um crescimento acelerado, associado a um grande impacto demográfico provocado pelos fortes fluxos migratórios do interior do estado, do Maranhão e do Ceará, uma vez que, por sediar o aparelho administrativo estatal e dispor de uma maior rede de serviços urbanos e sociais, acaba por tornar-se o centro de atração das populações rurais e de cidades com menos equipamentos e infraestrutura urbana (LIMA, 2010b). Outro fator que contribuiu significativamente para o crescimento urbano de Teresina consistiu na realização de obras federais de infraestrutura rodoviária, a construção das BR 316 e 343. A primeira favoreceu a continuidade da expansão na direção sul, já a segunda possibilitou a ocupação da zona leste da cidade, acrescentada pela construção da primeira ponte sobre o rio Poti na década de 1950 - Ponte Juscelino Kubistchek, a qual ligou a área central a esse novo espaço de expansão da cidade. Nessa senda, os primeiros bairros a se formarem nessa zona foram Fátima, Jóquei e São Cristóvão (LIMA, 2010a).

Teresina, atualmente, conta com 840.600 habitantes (IBGE, 2014), um incremento de 26.370 habitantes em relação aos 814.230 recenseados pelo IBGE em 2010. Conforme dados da tabela 1, registra-se que as décadas de 1960, 1970 e 1980 detiveram as maiores taxas médias geométricas de crescimento anual $(4,63 \%, 4,45 \% \mathrm{e}$ $5,53 \%$, respectivamente). Verifica-se que Teresina sai de uma população de $90.723 \mathrm{em}$ 1950 para 377.774 em 1980, mais que quadruplicando seu contingente populacional em 30 anos, o que interferiu diretamente em sua taxa de urbanização, posto sair de 56,67\% em 1950 para atingir 89,75\% em 1980. Nos decênios seguintes, a cidade segue registrando crescimento, mas com taxas mais baixas, refletindo uma tendência estadual, regional e nacional (LIMA, 2010b).

Tabela 1 - Dinâmica de crescimento da população de Teresina - PI. 1940-2010.

\begin{tabular}{|c|c|c|c|c|c|c|}
\hline \multirow[t]{3}{*}{ Ano } & \multirow[t]{3}{*}{ População total } & \multicolumn{4}{|c|}{ População } & \multirow{3}{*}{$\begin{array}{c}\text { Taxa média geométrica } \\
\text { de crescimento anual } \\
(\%)\end{array}$} \\
\hline & & \multicolumn{2}{|c|}{ Urbana } & \multicolumn{2}{|c|}{ Rural } & \\
\hline & & $\mathrm{N}^{\mathbf{0}}$ & $\%$ & $\mathrm{~N}^{\circ}$ & $\%$ & \\
\hline 1940 & 67.641 & 34.695 & 51,29 & 32.946 & 48,71 & - \\
\hline 1950 & 90.723 & 51.417 & 56,67 & 39.306 & 43,33 & 2,98 \\
\hline 1960 & 142.691 & 98.329 & 68,91 & 44.362 & 31,09 & 4,63 \\
\hline 1970 & 220.487 & 181.062 & 82,12 & 39.425 & 17,88 & 4,45 \\
\hline 1980 & 377.774 & 339.042 & 89,75 & 38.732 & 10,25 & 5,53 \\
\hline 1991 & 599.272 & 556.911 & 92,93 & 42.361 & 7,07 & 4,28 \\
\hline 2000 & 715.360 & 677.470 & 94,70 & 37.890 & 5,30 & 1,80 \\
\hline 2010 & 814.230 & 767.557 & 94,30 & 46.673 & 5,70 & 1,21 \\
\hline
\end{tabular}

Fonte: IBGE (1940, 1950, 1960, 1970, 1980, 1991, 2000, 2010)

Em relação à distribuição espacial da população pelo tecido urbano de Teresina, verifica-se, conforme dados do IBGE (2010), que as franjas da cidade, em todas as zonas, densificaram-se na primeira década de 2000 como consequência da expansão urbana e da mobilidade populacional para essas novas áreas. Esse movimento resulta da

${ }^{1}$ Para uma leitura mais aprofundada do processo de expansão urbana teresinense e suas implicações socioespaciais, principalmente horizontal, ver Lima (2010a; 2010b). 
busca de preços mais acessíveis do solo urbano por parte das classes populares para o consumo de moradia. Vale dizer que o aumento populacional dos bairros Santa Maria da Codipi e Chapadinha (zona Norte) tem como um dos fatores explicativos a construção da ponte do Poti Velho em 1992, uma vez que ligou esse espaço ao centro da cidade. Evidencia-se também que os bairros mais antigos da zona Norte, caso do Poti Velho, Buenos Aires dentre outros, permanecem com contingentes elevados em relação ao recenseamento de 2000, os quais, segundo Lima (2010b), historicamente se constituíram como os espaços ocupados pela população de baixa renda. Além disso, verifica-se que os bairros mais antigos, produzidos e ocupados a partir dos anos de 1970 e 1980, não somente na zona Norte, mas também nos outros espaços periféricos da cidade, os quais tornaram-se alvos de construção de conjuntos habitacionais por parte do poder público, acabaram se adensando e polarizando a concentração populacional.

Os dados populacionais e de renda dos teresinenses evidenciam as diferenciações socioespaciais presentes no tecido urbano da capital piauiense e se constituem evidências da dinâmica da (re)estruturação urbana porque passa a cidade, fenômeno semelhante que ocorre em outras cidades, como atestam os estudos de Marques e Bichir (2001), Ribeiro e Lago (1995), Spósito (2007). Na verdade, oito dos dez bairros com habitantes com maiores rendas se localizam na zona Leste, território da nova configuração da produção espacial dos serviços de saúde, sendo os outros dois localizados na zona Centro. É pertinente, pois, atentar para o fato de que esses bairros possuem contigüidade geográfica, o que revela a constituição de um espaço concentrador de riqueza, distinto da outra fração do território formada com setores de renda média e um grande contingente de renda baixa, diferenciando-se, internamente, portanto (quadro 1).

Quadro 1 - As 10 maiores rendas média por domicílios por bairros de Teresina - PI. 2010.

\begin{tabular}{||l|l|c|c|}
\hline Posição & \multicolumn{1}{|c|}{ Bairro } & Zona & Renda média em R $\$$ \\
\hline $1^{\mathbf{o}}$ & Jóquei & Leste & 12.033 \\
\hline $2^{\mathbf{o}}$ & Frei Serafim & Centro & 10.321 \\
\hline $3^{\mathbf{o}}$ & Fátima & Leste & 8.672 \\
\hline $4^{\mathbf{o}}$ & São Cristóvão & Leste & 8.547 \\
\hline $5^{\mathbf{o}}$ & Ininga & Leste & 7.819 \\
\hline $6^{\mathbf{0}}$ & Horto Florestal & Leste & 7.554 \\
\hline $7^{\mathbf{0}}$ & Morada do Sol & Leste & 6.885 \\
\hline $8^{\mathbf{o}}$ & Recanto das Palmeiras & Leste & 6.431 \\
\hline $9^{\mathbf{o}}$ & Nossa Senhora das Graças & Centro & 6.098 \\
\hline $10^{\mathbf{o}}$ & Santa Isabel & Leste & 5.545 \\
\hline
\end{tabular}

Fonte: IBGE (2010).

Dos 10 bairros com maior concentração de renda baixa, 4 encontram-se na zona Norte, 3 na Sul, 2 na Leste e 1 na Sudeste, tendo como uma de suas características comuns a localização nas franjas do tecido urbano (quadro 2). Nesse sentido, em relação à localização dos bairros, tem-se que enquanto os mais pobres se espraiam pelas áreas periféricas da cidade, os bairros mais ricos formam uma zona de concentração de riqueza, espaço central da zona Leste. Evidenciam-se, ademais, as desigualdades presentes na capital piauiense, tomadas a partir da comparação entre as áreas com as maiores e as menores rendas (quadros 1 e 2), ao verificar que o bairro Santa Isabel (R\$ 5.545,00 - o décimo mais rico) possui mais que o quíntuplo que a renda média do Samapi (R\$1.014,00 - o décimo mais pobre) e o Jóquei ( $\mathrm{R} \$ 12.033,00$ - maior renda) 
detém uma renda média 16 vezes maior que a do São Lourenço ( $\mathrm{R} \$ 714,00$ - menor renda).

Quadro 2 - As 10 menores rendas média por domicílios por bairros de Teresina. 2010.

\begin{tabular}{|l|l|c|c|}
\hline \multicolumn{1}{|c|}{ Posição } & \multicolumn{1}{|c|}{ Bairro } & Zona & Renda média em R\$ \\
\hline $1^{\mathbf{o}}$ & São Lourenço & Sul & 714,00 \\
\hline $2^{\mathbf{o}}$ & Santa Rosa & Norte & 778,00 \\
\hline $3^{\mathbf{o}}$ & Olaria & Norte & 805,00 \\
\hline $4^{\mathbf{o}}$ & Verde Cap & Sudeste & 839,00 \\
\hline $5^{\mathbf{o}}$ & Tabajaras & Leste & 858,00 \\
\hline $6^{\mathbf{o}}$ & Cidade Industrial & Norte & 878,00 \\
\hline $7^{\mathbf{o}}$ & Aroeiras & Norte & 889,00 \\
\hline $8^{\mathbf{o}}$ & Parque Jacinta & Sul & 961,00 \\
\hline $9^{\mathbf{o}}$ & Distrito Industrial & Sul & 986,00 \\
\hline $10^{\mathbf{o}}$ & Samapi & Leste & $1.014,00$ \\
\hline
\end{tabular}

Fonte: IBGE (2010).

As análises acerca da constituição do urbano e suas relações com as desigualdades de renda são substanciais para que se compreendam os processos de (re)estruturação urbana. Teresina, assim como vem ocorrendo em outras cidades brasileiras, principalmente as de grande e médio porte, caso de Fortaleza (MONTENEGRO JÚNIOR, 2012) e Petrolina (CRUZ, 2013), passa por transformações estruturais importantes.

$\mathrm{Na}$ análise desse processo em Teresina, tem-se que houve a partir da segunda metade do século XX a constituição de uma área residencial voltada para um público com alto poder de consumo, localizada na zona Leste, e evidencia uma das dinâmicas urbanas empreendidas sobre o espaço teresinense, em que houve a produção de territórios autossegregados, representados pelos bairros Jóquei Clube, Fátima, Planalto Ininga, Horto Florestal e São Cristóvão. Um dos fatores que contribuíram significativamente para essa realidade urbana foi a instalação, na década de 1970, do campus da Universidade Federal do Piauí nessa zona, empreendimento que exigiu do poder público a criação de infraestrutura viária, saneamento e urbanização dos bairros próximos, o que influiu na valorização desses espaços (ABREU, 1983). Contudo, ainda na década de 1950, esse espaço já se apresentava como área de expansão da cidade, com tendências de diferenciação socioespacial, posto que o primeiro empreendimento privado que marca o início desse processo refere-se ao lançamento do loteamento SOCOPO - Cidade Jardim, em 1952 (CASTELO BRANCO, 2012). Por outro lado, a construção da ponte Juscelino Kubistchek, concluída em 1957 e que ligou a Avenida Frei Serafim (via que separa a zona Norte da Sul) à rodovia BR-343, favoreceu significativamente a ocupação da margem direita do rio Poti, espaço que foi ganhando densidade nas décadas seguintes. Nesse sentido, as transformações nos estilos de vida, associadas às novas formas de consumo, lazer e desejos de maiores confortos, fizeram com que houvesse a expansão urbana para o novo espaço, o que repercutiu na perda de habitantes da região central, espaço antes habitado pela elite da capital piauiense (NASCIMENTO, 2011; ABREU, 1983), fato que ainda ocorre, conforme dados do IBGE (2010), pois o bairro Centro detinha 15.284 habitantes em 2000 e 12.180 em 2010 . 
Outro fenômeno que marca essa zona da cidade refere-se ao processo de verticalização que, iniciado nos fins dos anos de 1970 e com incrementos significativos nas décadas seguintes (ARAÚJO, 1993), foi promovido pela ação de promotores imobiliários e põe em relevo as lógicas da produção da segregação socioespacial urbana teresinense, uma vez que os bairros centrais dessa região se destacam, perante os demais, em valores econômicos, sociais e simbólicos relativos ao solo urbano (LIMA, 2001). Aliás, a consolidação dessa área em que habitam os estratos sociais de mais alta renda de Teresina, conforme Castelo Branco (2012), não foi alvo apenas da ação do mercado imobiliário, pois o Estado também contribuiu com a configuração atual, seja por meio da legislação, seja por investimentos em infraestruturas. Assim, a constituição desse espaço propiciou incrementos de diversas atividades voltados para um público com alto poder de consumo, como a venda de edifícios de elevado valor econômico, revendedoras e concessionárias de carros, restaurantes, casas de shows e eventos variados, lojas de decoração e móveis planejados, de artigos e produtos de grifes e serviços de saúde (CASTELO BRANCO, 2012; ARAÚJO, 1993). Enfim, as ações do estado e dos agentes privados na produção urbana de Teresina evidenciam práticas que tornam o espaço citadino como uma mercadoria a ser consumida segundo o poder aquisitivo de seus moradores, realidade vivida em outras cidades, conforme análises de Arantes (2002), Vainer (2002), Sánches (2001).

Em relação ao processo de verticalização, Teresina, quando comparada com outras capitais e cidades do nordeste, conforme apontam os estudos de Cruz (2013) e Santos Júnior (2008), registrou um crescimento tardio. Nesse sentido, Teresina possui um incremento em relação ao número de edifícios de forma lenta na primeira década do início desse processo, posto que, no final dos anos de 1970, contava com 61 construções verticais, 105 nos de 1980, um aumento de 44 unidades. Essa realidade toma uma inflexão no final dos anos de 1990, com um acréscimo de 136 edifícios, sendo na década de 2000 que o processo se consolida, com 169 novas construções. A espacialização desse processo evidencia que a zona Centro teve maior incremento na década de 1980, com 74 edificações desse porte, e diminuiu nos decênios seguintes, 58 na década de 1990 e 33 na de 2000. Verifica-se que a zona Leste robustece esse processo ao longo dos anos de 1990, com 74 construções verticais, mas é na década de 2000 que esse processo se consolida, com 131 novos edifícios, uma das evidências desse território como o mais propício a essa forma de produzir o espaço urbano (TERESINA, 2014).

O processo de verticalização na região central teresinense é representada, principalmente, pelos bairros Centro, Frei Serafim e Ilhotas (TERESINA, 2014). Nesse sentido, a expansão do processo de crescimento vertical para fins de moradia inicia-se no bairro Frei Serafim (1 edifício na década de 1970, 6 na de 1980, 15 na de 1990 e 9 na de 2000), seguido do Ilhotas (1 na de 1970, 1 na de 1980, 10 na de 1990 e 2 na de 2000). Destarte, o processo inicial de saída da população de alta renda do centro da cidade deu-se para os bairros da zona Leste (Jóquei e Fátima), em que as formas de moradias se constituíam, principalmente, em mansões e sítios, e nas adjacências do centro (Frei Serafim e Ilhotas), pelo que os prédios erguidos no bairro Centro - 40 na década de 1970, 26 na de 1980, 14 na de 1990 e 5 na de 2000 (TERESINA, 2014), evidenciam o decréscimo dessa atividade e clareia, também, a visibilidade da 
mobilidade da função residencial desse território para outras áreas da cidade, conforme Araújo (1993), Lima (2001), Teresina (2014) e Castelo Branco (2012).

A dinâmica do fenômeno da verticalização na zona Leste da cidade no período de 1970 a 2010 evidencia os incrementos dessa atividade na região e de sua consolidação como vetor de crescimento e investimento imobiliário, com efeitos diretos nos preços e na valorização do solo urbano. Os primeiros edifícios foram construídos, ainda na década de 1970, nos bairros São Cristóvão e Morada do Sol, espaço mais distante do bairro Centro quando se compara com os bairros Jóquei e Fátima, o que evidencia uma das práticas de promotores imobiliários, a seletividade e antecipação espacial (CORRÊA, 1989). Assim, uma vez construindo em uma área longínqua do Centro, em que se deixa um vazio urbano, busca-se, particularmente junto ao poder público, a instalação de infraestrutura urbana, o que faz com que haja uma valorização do solo urbano e traz vantagens para novos investimentos. Nessa direção, os decênios seguintes (1990 e 2000), uma vez que, na década de 1980, os bairros Fátima e Jóquei detinham apenas 1 e 2 edifícios respectivamente, se constituem o período de consolidação desse processo na zona Leste, com esse dois bairros apresentando os maiores quantitativos de edifícios nos de 1990 (8 e 13, respectivamente). No decênio posterior, isso mais que triplica, pela construção de 46 e 20 empreendimentos nos bairros Jóquei e no de Fátima, respectivamente, o que os colocam como os espaços mais valorizados na capital piauiense. Registra-se ainda que dois bairros, contíguos ao Jóquei e Fátima, também despontam como vetores dessa atividade, o São Cristóvão (1 edifício na década de 1970, 4 na de 1980, 13 na de 1990 e 14 na de 2000) e o Horto Florestal (que sai de 7 edifícios na década de 1990 para 13 no final da de 2000, revelando a expansão da área em que habitam as populações de mais alta renda da cidade. Essa expansão do processo de verticalização na zona Leste, principalmente nos bairros mais próximos do Jóquei e Fátima, é revelada também pelos bairros Campestre (1 edifício na década de 1980, 17 na de 1990 e 5 na de 2000) e Santa Izabel (1 edificação na década de 1990 e 11 na de 2000) (TERESINA, 2014).

Os dados indicam que o crescimento vertical da cidade possui um núcleo, representado pelos bairros Jóquei e Fátima, mas se espraia pelos bairros adjacentes (Horto, São Cristóvão, Campestre, Noivos e Santa Izabel), o que torna a zona heterogênea socioespacialmente. Uma das faces dessa diferenciação é indicada em Castelo Branco (2012), que mapeou os edifícios com maior número de pavimentos (os quais exigem exige uso de elevadores e encarecem os valores dos apartamentos), encontram-se no núcleo desse espaço, e à medida que as construções se afastam, diminuem-se as quantidades de pavimentos. Ainda conforme Castelo Branco (2012), modificações na legislação urbana foi empreendida para alterar a permissão de construção de edifícios acima de 10 pavimentos, uma vez que esses bairros ficam próximos ao aeroporto da cidade.

A construção de novos edifícios residenciais nos anos de 2011, 2012 e 2013 ainda se concentraram nos bairros da zona Leste, mas também se expandiram-se em outras zonas da cidade. Na zona Sul, tem-se o bairro Catarina, com 1 edificação em 2012 e 2 em 2013, na zona Norte, no bairro Primavera foram construídos 2 edifícios em 2011 e 2 em 2013. Na zona Sudeste, o bairro colorado desponta com 3 edifícios (1 em 2011, 1 em 2012 e 1 em 2013). Ainda nessa zona, nos bairros Gurupi e Verdecap surgiram 2 e 3 edifícios em 2013, respectivamente (TERESINA, 2014). 
Mas, é nos bairros da zona Leste que o processo de verticalização se intensifica, com a construção de 18 edifícios em 2011, 27 em 2012 e 39 em 2013. Em 2011, os bairros Campestre, São Cristóvão e Ininga se destacaram por contarem com 3 edificações cada, enquanto que o Jóquei e Fátima registraram 1 e 2 edifícios, respectivamente. Em 2012, destaca-se com o maior número de empreendimentos verticais o bairro Santa Isabel, com 12, seguido do Jóquei com 4. Em 2013, é o bairro Horto que registra o maior número, 15 no total, acompanhado pelo bairro de Fátima, com 10, e Jóquei com 7 edifícios construídos (TERESINA, 2014).

$\mathrm{Na}$ verdade, a dinâmica do processo de verticalização evidencia a redução, ao longo dos anos, das construções no bairro Centro e o incremento nos bairros Jóquei, Fátima e São Cristóvão desse novo padrão de moradia, condomínios verticais fechados. O Jóquei, por exemplo, mais que dobra seus empreendimentos ao longo da década de 2000 em comparação com a anterior (TERESINA, 2014). Verifica-se, portanto, que as construções na direção centro-sul vão diminuindo à medida que os bairros da zona Sul ficam mais afastados, encerrando-se nos bairros Santa Luzia, Parque São João e Morada Nova. Nas zonas Norte e Sudeste, esse fenômeno ainda é tímido quando comparadas às outras regiões, principalmente a Leste.

Outro elemento que marca o processo de reestruturação urbana por que vem passando Teresina no âmbito da produção residencial são os condomínios horizontais, principalmente a partir dos anos 2000. Trata-se de novas formas de morar que, estimulados pelos setores imobiliário e publicitário, (re)configuram as estruturas socioespaciais e permitem diferenciações no uso e apropriação do espaço urbano.

Essa nova forma de moradia na capital é alimentada pela difusão de um discurso ideológico e simbólico, que evocando valores, como segurança e convivência entre os pares, mobiliza as classes sociais mais ricas a apropriarem-se desses espaços. Esses desejos de diferenciações socioespaciais de algumas parcelas da sociedade, instigadas pelos meios publicitários vem se materializando nos condomínios horizontais fechados (atualmente 55 empreendimentos), os quais se expandem, principalmente, na zona Leste da cidade, preenchendo vazios urbanos entre a área de ocupação consolidada e os conjuntos habitacionais produzidos nas franjas da cidade (SILVA; LOPES; MONTEIRO, 2013).

Embora esses empreendimentos se concentrem na zona Leste, o mercado imobiliário busca outras áreas como espaços de expansão, o que revela uma de suas dinâmicas de produção espacial urbana na cidade, com destaque para as zonas Sul e Sudeste. Essas novas formas de moradias, voltadas para as classes média e alta, promovem uma série de mutações nas relações socioespaciais, a partir de processos como autossegregação, privatização de áreas públicas, homogeneização social, status de quem habita esses espaços e abandono dos espaços públicos da/na cidade, o que interfere diretamente nas práticas urbanas (CALDEIRA, 2003; GOMES, 2002). Assim, a busca do direito à cidade, dada à segmentação promovida por essas formas de viver e apropriar-se o/do urbano, vê-se fragilizada (LEFEBVRE, 2008).

A expansão urbana por meio do crescimento horizontal da cidade também tem ocorrido em Teresina por outros mecanismos, seja através da ocupação executada pelos pobres urbanos, seja pela ação do poder público municipal, ações que dinamizam a (re)estruturação urbana. É que a partir das ocupações, o poder público é demandado 
para fornecer as infraestruturas básicas, regularização fundiária, dentre outras (LEAL, 2007; LIMA, 2010a; 2010b; 2007; 2003).

Nessa direção, Lima (2010a) analisa uma história de luta por habitação popular a partir dos conflitos entre os moradores da favela COHEBE (zona Sul da cidade) e o poder público local nas décadas de 1970 e 1980, o que resultou na construção de um espaço específico para a remoção das famílias, no caso o bairro Promorar, localizado distante, naquele momento, do centro de Teresina, o que produziu um vazio urbano que foi se densificando ao longo das décadas posteriores a sua instalação.

Em Lima (2003) discutem-se as multifaces da pobreza urbana em Teresina a partir das representações simbólicas dos pobres citadinos. Na obra, a autora parte da interpretação da espacialização das classes menos favorecidas no espaço urbano e como os mesmos foram objetos de ações do poder público local na provisão da moradia, o que (re)configurou a produção da (re)estruturação urbana da capital.

Lima (2007) analisou a política de investimentos na infraestrutura viária teresinense no período de 1997 a 2004, com vistas a compreender o padrão de investimentos, as tendências e espacialização dos gastos, o que revela o perfil das ações públicas no espaço urbano. Conclui a autora que no referido período as inversões se caracterizaram por pequenas obras, de baixo investimento e com concentração nas extremidades das zonas periféricas, mas com algumas ações pontuais em bairros antigos da cidade, o que concretiza, portanto, uma das facetas da (re)estruturação urbana em Teresina.

Lima (2010b) incursiona acerca da gestão urbana e políticas de habitação social a partir da experiência da urbanização de favelas, particularmente o programa desenvolvido pelo poder público municipal denominado de "Vila-Bairro". Conclui a autora que

[...] O Vila-Bairro ficou praticamente restrito a obras de infraestrutura física e um atendimento parcial na maioria das áreas, engendrando-se um padrão centrado nos aspectos físico-urbanísticos e uma hierarquização pervesa, na qual se privilegiou os grandes assentamentos, já consolidados, os reassentamentos antigos e novos, e os aglomerados localizados nas franjas urbanas. Isso produziu, de um lado, algumas poucas áreas com níveis razoáveis de urbanização e, de outro, uma maioria com baixa provisão de serviços e equipamentos urbanos (LIMA, 2010b, p. 195).

As reflexões produzidas por Lima (2010a; 2010b; 2007; 2003) indicam que as ações estatais promovem uma reconfiguração espacial urbana a partir de obras de infraestrutura física, o que influi nas condições da habitação das populações pobres, na provisão de equipamentos e serviços urbanos e na dinâmica socioespacial da cidade, interferindo, portanto, no processo de reestruturação urbana de Teresina.

Outra forma de intervenção do Estado é por meio da legislação que trata do uso e ocupação do solo urbano. É a partir dela que se acompanha, por exemplo, a expansão da cidade, as permissões para os usos, os incentivos de determinadas atividades comerciais e de serviços. É com base nesse escopo jurídico que a ação dos produtores imobiliários e suas produções espaciais se baseiam, um dos elementos que contribuem para a concretização dos processos, como o de verticalização e a construção de condomínios horizontais fechados na realidade urbana de Teresina, por exemplo, conforme análises de Castelo Branco (2012) e Lima (2001). Esse crescimento da cidade 
nem sempre é acompanhado pela legislação, nem por ações efetivas do poder público na provisão de infraestrutura urbana, fato notado na última atualização da zona urbana e delimitação dos bairros da cidade, a qual ocorreu com a Lei $n^{\circ} 4.423$ de julho de 2013 (TERESINA, 2013), e que delimitou no perímetro urbano áreas já em processo de consolidação de ocupação significativa, caso do bairro Chapadinha (zona Norte) e bairro Pedra Miúda (zona Sul).

Ao longo da década de 2000 a política habitacional instituída pelo Governo Federal a partir de disponibilização de crédito para a aquisição da casa própria ensejou alterações substanciais no tecido urbano teresinense. Em 2009, foi lançado o programa "Minha Casa, Minha Vida" (PMCMV), pela Lei n ${ }^{\circ} 11.977$, de 7 de julho de 2009 (BRASIL, 2009), o qual vem promovendo a construção de extensos conjuntos habitacionais voltados para os setores sociais de média e baixa renda. Esse programa divide seus beneficiários em 3 faixas: 1) contempla famílias com renda entre 0 a 3 salários mínimos; 2) é voltada para os que detém renda de 3 a 6 salários mínimos e a 3) volta-se para quem possui renda de 6 a 10 salários mínimos.

A produção habitacional em Teresina, de 2004 a 2012, conforme demonstra quadro 7, promoveu a construção de 33.089 unidades unifamiliares, o que propiciou o crescimento urbano de forma significativa. Já as unidades multifamiliares contabilizamse 4.921 no período, o que resultou na soma de 38.010 unidades habitacionais espraiadas pela cidade. A espacialização dessas unidades habitacionais pelo tecido de Teresina revela que os conjuntos voltados à população de baixa renda $(0$ a 3 salários mínimos) se encontram nas extremidades da cidade. Na zona Norte localizam-se 3 nos bairros Aroeiras (3) e no bairro Chapadinha (1), na Leste, Vale do Gavião (4) e no Cidade Jardim (1), mas é a zona Sul que concentra o maior número de empreendimentos: bairro Portal da Alegria (7), Pedra Miúda (2), bairros Angélica (1), Brasilar (1), Catarina (1) e São Lourenço (1). A zona Sul também se destaca na construção de habitações para a faixa de 3 a 6 salários mínimos, com 12, encravados, também nas franjas urbanas. Ainda nessa faixa, a zona Sudeste aparece com 5 empreendimentos desse porte (CEF, 2012).

Esse mapeamento mostra que a expansão urbana nas áreas periféricas, nas direções Sul, Norte e Leste, segue a tendência dos anos de 1990, posto que se consolida como vetores de crescimento da cidade. São nesses espaços que se dão as ocupações dos grupos sociais de menores rendas. Leite (2013) infere que é nesses limites em que há maior carência de equipamentos de serviços urbanos (saúde, educação e transporte), o que torna a vida dessas populações mais onerosas, caso o poder público não atue na urbanização de tais espaços.

Outra faceta desse processo de reestruturação urbana que vive Teresina é o movimento que ocorre no âmbito das atividades comerciais e de serviços, caracterizado pela sua expansão e territorialização em outras áreas da cidade. Destaquem-se, entre estes, os serviços educacionais, bancários de hospedagem, lazer e entretenimento e comerciais.

No segmento educacional a inflexão se deu pela expansão do setor privado ${ }^{2}$ do ensino superior, iniciado em 1985, com a CESVALE, construída na zona Leste da cidade, área que já se modificava com os processos de ocupação e uso do solo. Além

${ }^{2}$ Os dados referem-se às instituições credenciadas pelo MEC, excluindo-se as que se dedicam especificamente ao ensino à distância. 
desta, até 1999 foram criadas outras sete faculdades: uma em 1992, uma em 1994, duas em 1998 e três em 1999. Mas foi a partir dos anos de 2000 que se verificou maior expansão dessa atividade com a criação de 18 instituições, um amento de 64,3\% em relação ao período anterior (BRASIL, 2014).

A distribuição espacial dessas instituições é um traço que chama a atenção no processo de territorialização desses serviços. Verifica-se que o seu crescimento se dá em todas as zonas da cidade, mas com destaque para a zona Centro, com 9 instituições e as zonas Sul, Sudeste e Norte detém 2, 2 e 1, respectivamente. Mas é na Leste que se concentra a maior parte delas, 12 no total. Essas instituições de ensino produzem fluxos significativos de pessoas, mercadorias e serviços, o que influencia, a partir de suas territorializações, a produção socioespacial.

No setor bancário, o Centro possui a maior quantidade de agências, 19 no total. Já a zona Leste detém 16, a Sul, 6, a Sudeste, 3, e Norte com 2, perfazendo 46 unidades na capital. Com efeito, as instituições do setor público, como Banco do Brasil (BB) e a Caixa Econômica Federal (CEF), tem mais unidades, 17 e 10, respectivamente (FEBRABAN, 2014). Observa-se também que esses dois bancos são os que mais se distribuem pelo tecido espacial, atuando em todas as zonas da cidade, o que evidencia sua expansão, ao passo que os grupos financeiros privados se concentram mais na área central e na zona Leste, uma vez que todos, com exceção do HSBC - Banco Múltiplo, têm postos de atendimento nos bairros dessa região, o que revela que esse espaço se constitui como uma nova centralidade, atraindo um fluxo significativo de pessoas e capital.

Em relação aos serviços de hotelaria, constata-se uma concentração desses na área central da cidade, com 11 hotéis, embora a zona Leste venha se constituindo área de expansão dessa atividade, com 5, a Sul, com 4, e a Norte, com 2. Destaque-se a instalação de grandes redes, principalmente na zona Leste, como o caso do Gran Hotel Arrey, inaugurado em junho de 2012, com 200 apartamentos, mais um empreendimento de porte no setor e fator de consolidação das novas territorializações de prestação de serviços na cidade.

O setor de revenda de carros novos também é uma das faces das novas dinâmicas da produção espacial em Teresina. Sua localização demonstra a forte procura da zona Leste como área preferencial para a instalação desse tipo de serviço, uma vez que na mesma se instalaram 16 concessionárias, de um total de 22 estabelecimentos, distribuídos nos bairros São Cristóvão, Noivos e Jóquei (7, 4 e 2 unidades, respectivamente), nos quais habitam os estratos de mais alta renda da cidade (IBGE, 2010). Dessas, 13 se territorializam ao longo da Avenida João XXIII, o que torna esse espaço em um eixo especializado na oferta desse serviço, uma coesão espacial (CORRÊA, 1989), que atrai um fluxo significativo de pessoas interessadas na aquisição de carros novos.

No conjunto das atividades ligadas ao lazer e entretenimento, cresceu a rede de restaurantes teresinenses, em que se realça, que dos 33 listados em um sítio da web, mantido pelo poder público municipal, apenas 1 encontra-se fora da zona Leste, o Flutuante, localizado no Parque Encontro dos Rios, zona Norte, um dos pontos turísticos da capital piauiense. No âmbito da territorialização desses serviços, os oferecidos pelo Grupo "Restaurantes e Churrascarias Favorito", dispõe de gastronomia variada e requintada em sua rede de estabelecimentos, os quais territorializam-se nos 
bairros Fátima, Jóquei e São Cristovão, espaços em que habita a população de alta renda da cidade, o que, conforme reflexões de Corrêa (2007) e Carlos (2007), se constituem em mais um elemento de diferenciação socioespacial dessa fração espacial de Teresina.

A espacialização dessas atividades comerciais e de serviços registra a concentração na zona Leste da cidade, o que evidencia uma diferenciação socioespacial que fragmenta a urbe e produz fluxos significativos de pessoas, mercadorias e informações. Observa-se o pouco adensamento dessas atividades (faculdades, serviços bancários, shoppings e concessionárias de carros), nas zonas Norte, Sul e Sudeste, enquanto que a zona Centro e Leste concentram a maior parte de todos os serviços. Uma das faces da diferenciação socioespacial manifesta-se na localização dos três shoppings da cidade, posto que o localizado no bairro Centro, Shopping da Cidade, é voltado para um público popular, enquanto que os dois da zona Leste voltam-se para as camadas sociais mais ricas.

As transformações urbanas recentes experimentadas por Teresina apontam para a formação de subcentros, como examinado por Lima (2011). O autor analisou o bairro Itararé, na zona Sudeste como espaço de constituição de um subcentro. Nesse espaço, particularmente as atividades comerciais e de serviços prestados ao longo da Avenida José Francisco de Almeida Neto (popularmente conhecida como Av. Principal do Dirceu) atendem à população dos bairros do entorno, reduzindo as necessidades de ida até o centro da cidade. É que, segundo o autor, a presença de atividades bancárias, comerciais e de saúde e educação exercem uma atração sobre toda a zona Sudeste.

$\mathrm{Na}$ infraestrutura educacional, esse espaço dispõe de 23 escolas públicas (da préescola ao ensino médio), um campus da Universidade Estadual do Piauí - UESPI, uma escola de educação básica e profissional mantida pela Fundação Bradesco (desde 1982). No âmbito da saúde, há um hospital e uma maternidade públicas, além de clínicas e laboratórios privados.

As atividades comerciais desenvolvidas ao longo da Avenida Principal são complementadas por dois mercados públicos e um grande supermercado, que atendem o contingente populacional da região em suas compras diversas. Os serviços bancários são realizados especialmente pelas agências do Banco do Brasil, Caixa Econômica Federal e Banco do Nordeste. Trata-se de elementos da estrutura urbana presentes nesse espaço que ensejam a produção e manutenção de fluxos permanentes de pessoas, capital e informações, configurando-lhe como um subcentro. Ou seja, além do centro principal, existe um outro que o complementa e materializa uma das faces do processo de reestruturação urbana da capital piauiense (LIMA, 2011).

O centro principal de Teresina vem sofrendo reestruturação nas últimas décadas, especialmente com a intervenção da prefeitura sobre o comércio informal, com a retirada dos vendedores ambulantes das ruas para um local específico, o Shopping da Cidade $^{3}$. Nesse sentido, a área central passou por transformações socioespaciais decorrentes da execução dos projetos contidos no Plano Diretor da Cidade, denominado “Teresina - Agenda 2015". Na verdade, o centro exerce a centralidade máxima de

${ }^{3}$ A ideia de construção do Shopping da cidade visou à desobstrução de vias públicas do centro, as quais eram ocupadas por vendedores ambulantes e geravam problemas de naturezas diversas. Vale dizer que esse processo foi repleto de dissensos e consensos entre os atores principais dessa ação - poder público municipal, lojistas e vendedores ambulantes. Para uma leitura mais aprofundada ver Silva (2014). 
Teresina, o que atrai fluxos intra e interurbano de forma intensa, uma vez que congrega uma diversidade de atividades comerciais e de serviços que atendem aos anseios de consumo da população demandante. Essa condição produz problemas relacionados a acessibilidade, mobilidade, conflitos de territorialidades, dentre outros (SILVA, 2014).

É pertinente, outrossim, a análise de Costa (2014) sobre as transformações socioespaciais ocorridas na área concentradora dos serviços de saúde de Teresina, localizadas no bairro Centro, no período de 2000 a 2013, na qual põe sob escrutínio as formulações do Plano Diretor para esse espaço. Suas reflexões concluem que 1) predomina ainda no espaço uma infraestrutura deficitária para trânsito de veículos e pessoas; 2) continuam as casas de pensões a ter as mesmas estruturas físicas; 3) não se efetivou o projeto voltado para os eventos de saúde; 4) mantêm-se presentes nas ruas os vendedores ambulantes, sem um espaço específico que os acomodem; 5) tem conflitos pela (re)produção de territorializações, desterritorializações e reterritorializações que têm gerado problemas para os diversos sujeitos produtores desse espaço (donos de pensões, proprietários de hospitais, clínicas, laboratórios e farmácias, taxistas e mototaxistas, agenciadores(as) de clientes para estabelecimentos médicos, vendedores ambulantes e Estado).

As conclusões de Costa (2014) remetem a coexistência de dois circuitos da economia urbana (SANTOS, 2004) que se concretizam no espaço concentrador dos serviços de saúde da capital piauiense. Ou seja, se por um lado há agentes produtores do espaço integrados às formas mais modernas de inserção nos setores econômicos, por outro coexistem sujeitos que se inserem a partir de formas tradicionais de busca de sobrevivência econômica, o que evidencia diferenciações socioespaciais (CARLOS, 2007; CORRÊA, 2007) no bojo do território dos serviços de saúde da área central, como destacado em Bueno (2008).

Outra atividade que ativou a produção espacial urbana recente (década de 1990) de Teresina refere-se à instalação na cidade de dois shoppings centers voltados para as camadas sociais mais ricas (Riverside - inaugurado em 1996, e Teresina Shopping - em 1997), que conferiram uma nova dinâmica aos setores do comércio e do lazer e contribuíram para a valorização do solo urbano nessa fração do território (zona Leste). Ruiz (2004), ao analisar o papel dos shoppings nos processos de segregação, exclusão e inclusão em Presidente Prudente (SP), desenvolve um raciocínio, que também vale para Teresina, segundo o qual essa forma urbana é construída para um público específico (média e alta renda) que deseja consumir em um único espaço os produtos requeridos, sem necessidade de deslocar-se ao centro principal, o que faz com que esses templos de consumo modifiquem significativamente o fluxo dos transportes coletivos, que têm os seus roteiros de linhas de ônibus refeitos para atender à população que os demanda.

No âmbito do lazer proporcionado por esses modelos arquitetônicos de consumo, destaque-se o fato de que são eles os únicos que detém, por exemplo, os cinemas da capital (Riverside, 3 salas; Teresina Shopping, 5), e exerce uma centralidade sobre toda a cidade. Ademais, as praças de alimentação dos shoppings, a par de suas lojas, atraem números significativos de usuários, da capital e do interior do estado.

Esses modelos de empreendimentos configuram a policentralidade, conforme argumentação de Spósito (2013), pelo que se afirma que, a atual Teresina, além de multicêntrica, é policêntrica, uma vez que seus subcentros, concretizados, por exemplo, nos shoppings, concorrem com o centro principal, não se atendo apenas à 
complementariedade de atividades comerciais e de serviços. Assim, a capital piauiense é, hoje, poli(multi)cêntrica.

Os shoppings dinamizam, ainda, de forma significativa, as atividades recreativas em suas proximidades, ao tornarem as avenidas Cajuína e Raul Lopes como grandes corredores de práticas de entretenimento, como o Parque Potycabana, recentemente reinaugurado (2013), que possibilitou o exercício de esportes diversos, como caminhada e a realização de festividades, o Espaço Teresina - área para grandes shows e eventos, como a cidade junina, e outros espetáculos que atraem multidões para esse local, sem dizer do trecho da Raul Lopes que serve para caminhada e ciclismo, entre outros, e das trilhas que margeiam o rio Poti, na Avenida Marechal Castelo Branco.

A reestruturação urbana é, também, analisada em Leite (2013), quando discute o impacto da mobilidade e acessibilidade nas transformações e (re)produção do espaço urbano teresinense. Com o auxílio dos sistemas de informação geográfica (SIGs), discutiu a autora alguns indicadores de sustentabilidade urbana para a capital piauiense, concluindo que as áreas de maior acessibilidade situam-se na área central da cidade, particularmente a Avenida Frei Serafim e seu entorno, e as de menores facilidades de acesso se encontram nos extremos de todas as outras zonas.

As análises de Leite (2013) afirmam que, aproximadamente, $30 \%$ da população gasta entre 30 minutos e duas horas entre a residência e o trabalho, tempos pela dimensões da cidade e a rede viária, considerado excessivo. Esse dado se agrava, principalmente, para as zonas Sudeste e Leste, nas franjas dessas regiões, em razão do ineficiente sistema de transportes coletivos, cuja baixa disponibilidade e freqüência dificulta o deslocamento da força de trabalho, constituindo-se um dos fatores que ampliam, para usar um conceito de Kowarick (1979), a espoliação urbana sobre os trabalhadores. Enfim,

[...] Considerando-se os fatores relacionados à acessibilidade aos bens e serviços, ficou claro que alguns deles, como as distâncias às escolas municipais, às vias de tráfego de transporte público e às zonas comerciais proporcionam uma boa acessibilidade, enquanto outros, como as distâncias aos postos de saúde, ao centro urbano e ao trabalho, comprometem a acessibilidade plena e a mobilidade urbana (LEITE, 2013, p. 145).

Ainda no âmbito da acessibilidade e seus fomentos para a expansão da ocupação urbana, fluidez no tráfego de veículos e reestruturação da cidade, destaca-se a construção de pontes em Teresina, a qual possui dez construções desse porte: Ponte João Luís Ferreira - 1939 (Ponte Metálica) - conecta a Av. Miguel Rosa (Teresina) à Av. Teresina (Timon); Ponte Juscelino Kubitschek - 1957 (Ponte da Frei Serafim) - faz a ligação da Avenida João XXIII (Zona Leste) à Avenida Frei Serafim (Centro da Cidade); Ponte Engenheiro Antônio Noronha - 1972 (Ponte Nova) interliga Teresina pelo Bairro Tabuleta à Cidade de Timon (zona Sul); Ponte Deputado Paulo Ferraz (1977) - liga o Bairro Tancredo Neves (zona Sudeste) à Rodoviária de Teresina (zona Sul); Ponte Ministro Petrônio Portella - 1979 (Ponte da Primavera) interliga a Avenida Petrônio Portela (Zona Norte) à Avenida Universitária (Zona Leste); Ponte Antônio Mariano Castelo Branco - 1992 (Ponte do Poty Velho) - conecta o Bairro Poty Velho à Santa Maria da Codipi (zona Norte); Ponte Wall Ferraz (1995) liga a Av. Higino Cunha (Zona Sul) à Av. Cajuína (Zona Leste); Ponte José Sarney - 
1997 (Ponte da Amizade) - liga a Av. Maranhão (Teresina) à Av. Piauí (Timon); Ponte Estaiada João Isidoro França (2010) - liga a Av. Rio Poty (Zona Leste) à Av. Alameda Parnaíba (Zona Norte); Ponte Leonel Brizola - 2011 (Ponte do Mocambinho) - liga o Bairro de Mocambinho (zona Norte) ao Bairro Pedra Mole (zona Leste) (TERESINA, 2008).

Das dez pontes existentes em Teresina, quatro delas interligam a zona Leste a zona Centro da cidade, considerada como o principal eixo de circulação por transporte individual da capital (TERESINA, 2008), uma das evidências de como as ações públicas fomentam a valorização de uma dada região da cidade e promovem processos de (re)estruturação urbana. Uma dessas ações recentes consistiu na construção da ponte Estaiada João Isidoro França (inaugurada em 2010), a qual tornou-se outra via de ligação entre a área central e a zona Leste, a partir da Avenida Dom Severino, o que permitiu uma maior acessibilidade ao centro da cidade, conforme Castelo Branco (2012). Outra que merece destaque e a Ponte do mocambinho (inaugurada em 2011), posto ter fomentado o aumento da ocupação da zona Norte da cidade, pós rio Poti, facilitando o fluxo de transportes e de pessoas.

Viana (2013) desenvolve um estudo da atividade extrativa mineral de materiais utilizados na construção civil, concluindo que esse processo se insere na e influencia a dinâmica de reestruturação urbana em Teresina, provocando impactos socioambientais significativos. É que ambientalmente se têm impactos positivos e negativos, diretos e indiretos, imediatos, de curto, médio e longo prazo, os quais se materializam nos meios físico, biótico e antrópico, e socialmente pode haver benefícios nas áreas de habitação, infraestrutura e geração de emprego e renda.

As dinâmicas urbanas para a produção e reprodução do capital ensejam, portanto, transformações que se refletem em processos de (re)estruturações das cidades. Nesse cenário, Teresina aparece com mutações nas centralidades exercida pelas atividades comerciais e de serviços, em seus padrões habitacionais, nos usos e ocupação do solo urbano. As lógicas dessa dinâmica conformam a capital piauienses como poli(multi)cêntrica e requer compreensões diversas, para que se entendam as territorializações, desterritorializações e reterritorializações dos variados agentes produtores do espaço citadino.

$\mathrm{Na}$ verdade, o espaço citadino, conforme Arantes (2002), Vainer (2002) e Sánches (2001), ao serem incorporados à lógica de mercado ganham a conformação de cidade mercadoria, a qual é apropriada de forma diferenciada pelas diversas classes sociais, o que torna as diferenciações socioespaciais mais visíveis e exige do poder público medidas que equalizem tais disparidades.

\section{Conclusão}

As transformações vividas pelas cidades fazem parte das novas lógicas de produção do espaço urbano, posto que envolvem diversos agentes que buscam, incessantemente, capitalizar recursos, o que torna o espaço, no bojo do sistema de produção, uma mercadoria. Nessa direção, as atividades comerciais e de serviços constroem novas localizações, dinamizam a centralidade e promovem a (re)estruturação do urbano e das urbes.

Em Teresina, esses aspectos são percebidos, sob diversos ângulos, pela análise das atividades comerciais e de serviços educacionais, bancários e de lazer e 
entretenimento, produção habitacional, etc. Os debates construídos afirmam que Teresina configura-se atualmente como uma cidade poli(multi)cêntrica, com uma dinâmica díspar e em cada fração espacial citadina, sendo a sua região mais propícia à ampliação das relações de produção a zona Leste, espaço de moradia dos grupos sociais de mais alta renda, que atrai diversos elementos produtores de uma diferenciação socioespacial na cidade e no próprio entorno para a consolidação de um subcentro, caso dos serviços de saúde.

Destarte, a centralidade remete a capacidade de atração que uma área exerce sobre os espaços que lhes são adjacentes, com foco, principalmente, nas atividades comerciais e de serviços, as quais se localizam de forma concentrada e geram fluxos permanentes de pessoas e mercadorias (SPÓSITO, 2002). Esse fenômeno que em Teresina, coincidiu historicamente com o seu núcleo original, presidiu o desenho urbano até o fim da década de 1980, mas vem sofrendo modificações espaciais significativas, conforme apontam distintos estudos (CASTELO BRANCO, 2012; LIMA, 2011; 2001; ARAÚJO, 1993), uma vez que o crescimento populacional e adensamento urbano promoveram(em) dinâmicas socioespaciais relevantes nos setores habitacionais, de atividades comerciais e de serviços, configurando uma reestruturação urbana que se acentuou nas décadas de 1990 e 2000.

\section{Referências}

ABREU, I. G. O crescimento da zona leste de Teresina: um caso de segregação?. 1983. Dissertação (Mestrado em Geografia) - Universidade Federal do Rio de Janeiro, Rio de Janeiro, 1983.

ARANTES, Otília. Uma estratégia fatal: a cultura das novas gestões urbanas. In: ARANTES, Otília; VAINER, Carlos B.; MARICATO, Ermínia (Org.).A cidade do pensamento único: desmanchando consensos. Petrópolis-RJ: Vozes, 2002, p. 11-73.

ARAÚJO, J. L. L. A verticalização como segregação espacial em Teresina. Revista Espaço-Tempo, Teresina, v.1, n. 3, p. 45-68, maio 1993.

BRASIL, M. da E. Instituições de Educação Superior e Cursos Cadastrados 2014. Disponível em: <http://emec.mec.gov.br>. Acesso em: 10 de Jun. 2014. Presidência da República. Lei Ordinária no 11.977, de 7 de julho de 2009. Dispõe sobre o Programa Minha Casa Minha Vida e dá outras providências. Diário Oficial [da] República Federativa do Brasil. Disponível em: www.planalto.gov.br/ccivil_03/_ato2007-2010/2009/lei/111977.htm. Acesso: 8 out. 2010.

BUENO, P. H. C. As casas de pensões do pólo de saúde de Teresina: produção espacial e políticas públicas. 2008. 128 f. Dissertação (Mestrado em Políticas Públicas) - Universidade Federal do Piauí, Teresina, 2008.

CALDEIRA, T. P. Cidade de Muros: crime, segregação e cidadania em São Paulo. São Paulo: Edusp, 2003.

CAIXA ECONÔMICA FEDERAL. Empreendimentos habitacionais construídos e/ou em construção em Teresina/PI. 2012.

CARlOS, A. F. A. A diferenciação socioespacial. Revista Cidades, Presidente Prudente-SP, v.4, n.6, p. 45-60, 2007. A cidade. São Paulo: Contexto, 1992. 
CASTELO BRANCO, A. F. V. A ação do Estado e do mercado imobiliário no processo de segregação socioespacial em bairros da zona Leste de Teresina. 2012. 189 f. Tese (Doutorado em Geografia) - Universidade Estadual Paulista, Rio Claro-SP, 2012.

CORRÊA, R. L. Diferenciação socioespacial, escala e práticas espaciais. Revista Cidades, Presidente Prudente-SP, v.4, n.6, p. 61-72, 2007.

Estudos sobre a rede urbana. Rio de Janeiro: Bertrand Brasil, 2006.

O espaço urbano. São Paulo: Ática, 1989.

COSTA, J. K. B. da. Demandas por serviços de saúde e as transformações socioespaciais na área central de Teresina. 2014. 118f. Dissertação (Mestrado em Geografia) - Universidade Federal do Piauí, Teresina, 2014.

CRUZ, P. F. de S. Reestruturação urbana em Petrolina (PE): um olhar a aprtir da implantação de novos produtos imobiliários. 2013. 163f. Dissertação (Mestrado em Planejamento Urbano e Regional), Universidade Federal do Rio Grande do Sul, Porto Alegre, 2013.

FAÇANHA, A. C. A evolução urbana de Teresina: agentes, processos e formas espaciais da cidade. 1998. Dissertação (Mestrado em Geografia) - Universidade Federal de Pernambuco, Recife, 1998.

GOMES, P. C. da C. A condição urbana: ensaios de geopolítica da cidade. Rio de Janeiro: Bertrand, 2002.

GOTTDIENER, M. A produção social do espaço. São Paulo: EDUSP, 1997.

IBGE. Estimativa da população 2014. Disponível em: <www.ibge.gov.br/home/estatistica/populacao/estimativa2014>. Acesso em: 07 de set. 2014.

Censo demográfico 2010. Disponível em: <www.ibge.gov.br>. Acesso em: 10 jan. 2012.

Censo demográfico 2000. Disponível em: 〈www.ibge.gov.br〉. Acesso: 10 jan. 2012.

2012.

Censo demográfico 1991. Disponível em: 〈www.ibge.gov.br〉. Acesso: 10 jan. _. Censo demográfico 1980. Disponível em: 〈www.ibge.gov.br〉. Acesso: 10 jan. 2012. 2012.

Censo demográfico 1970. Disponível em: <www.ibge.gov.br>. Acesso : 10 jan. _. Censo demográfico 1960. Disponível em: 〈www.ibge.gov.br〉. Acesso: 10 jan. 2012. 2012.

Censo demográfico 1950. Disponível em: <www.ibge.gov.br〉. Acesso: 10 jan. 2012 .

FEDERAÇÃO BRASILEIRA DE BANCOS. Listas dos Bancos Associados. Disponível em: < http://www.buscabanco.org.br/AgenciasBancos.asp>. Acesso em 10 de Jun. 2014.

LEAL, M. N. A relação entre o governo municipal de Teresina e a Associação de Moradores da Vila Wall Ferraz para a provisão do direito ao habitar. 2007. 181f. 
Dissertação (Mestrado em Políticas Públicas), Universidade Federal do Piauí, Teresina, 2007.

LEFEBVRE, H. A revolução urbana. 3 reimp. Tradução de Sérgio Martins. Belo Horizonte: Ed. UFMG, 2008.

LEITE, N. B. F. Expansão urbana e seus efeitos sobre a mobilidade e acessibilidade avaliada com o auxílio dos sistemas de informação geográfica (SIG) em TeresinaPI. 2013. 165f. Tese (Doutorado em Geografia), Universidade Federal de Minas Gerais, Belo Horizonte, 2013.

LIMA, A. J. Favela Cohebe: uma história de luta por habitação popular. 2 ed., Teresina: EDUFPI; Recife: Bagaço, 2010a.

Gestão urbana e políticas de habitação social: análise de uma experiência de urbanização de favelas. São Paulo: Ed. Annablume, 2010b.

Padrão de investimento em infra-estrutura viária: o caso de Teresina - PI. In: Anais III Jornada Internacional de Políticas Públicas. São Luis, 2007.

As multifaces da pobreza: formas de vida e representações simbólicas dos pobres urbanos. Teresina: Halley, 2003.

LIMA, P. H. G. A ocorrência da policentralidade em Teresina-PI: a formação de um subcentro na região sudeste. 2011. 204f. Tese (Doutorado em Geografia) Universidade Estadual Paulista, Rio Claro-SP, 2011.

Promoção imobiliária em Teresina/PI: uma análise do desenvolvimento da produção privada de habitações - 1984/1999. 2001. 101 f. Dissertação (Mestrado em Desenvolvimento Urbano) - Universidade Federal de Recife, Recife, 2001.

LIMONAD, E. Urbanização e organização do espaço na era dos fluxos. In: SANTOS, Milton et al. Território, territórios: ensaios sobre o ordenamento territorial. 2. ed. Rio de Janeiro: DP\&A, 2006.

MARQUES, E. C.; BICHIR, R. M. Estado e espaço urbano: revisitando criticamente as explicações sobre as políticas urbanas. Curitiba: Revista Sociologia Política, n. 16, Jun/2001, p. 9-29.

MONTENEGRO JÚNIOR, I. R. P. Uma metrópole em transição: reestruturação produtiva e a emergência do turismo na RM de Fortaleza-CE. 2112. 363f. Tese (Doutorado Interinstitucional em Arquitetura e Urbanismo). Universidade de São Paulo, São Paulo, 2012.

MONTESSORO, C. C. L. Centralidade urbana e comércio informal: os novos espaços de consumo no centro de Anapólis - GO. 2006. 383 f. Tese (Doutorado em Geografia) - Universidade Estadual de São Paulo, Presidente Prudente-SP, 2006.

NASCIMENTO, F. A. Teresina, a capital que nasceu sob o signo do moderno e da pobreza. In: SIMPÓSIO NACIONAL DE HISTÓRIA, 21., 2011, São Paulo. Anais... São Paulo: ANPUH, 1994. P. 1-15. Disponível em: <http://www.snh2011.anpuh.org/resources

/anais/14/1300477414_ARQUIVO_Teresinamodernaanpuh2011.pdf>. Acesso em: 15 dez. 2013.

A cidade sob o fogo: modernização e violência policial em Teresina (1937-1945). Teresina: Fundação Cultural Monsenhor Chaves, 2002

OFFE, C. Problemas estruturais do Estado capitalista. Tradução Bárbara Freitag. Rio de Janeiro: Tempo Brasileiro, 1984.

KOWARICK, L. A espoliação urbana. Rio de Janeiro: Paz e Terra, 1979. 
QUEIROZ, T. J. M. Os literatos e a república: Clodoaldo Freitas, Higino Cunha e as tiranias do tempo. Teresina: Fundação Cultural Monsenhor Chaves, 1994.

RIBEIRO, L. C. de Q.; LAGO, L. C. do. Dinâmica metropolitana e os novos padrões de desigualdade social. São Paulo em Perspectiva, n.9, 1995.

RODRIGUES, A. de S. R. A produção do espaço urbano de Juiz de Fora/MG: dinâmicas imobiliárias e novas centralidades. 2013. 291f. Tese (Doutorado em Geografia), Universidade Federal de Minas Gerais: Belo Horizonte, 2013.

RUIZ, J. A. M. Shopping centers: segregação, exclusão e inclusão. Análise a partir de bairros residenciais em Presidente Prudente-SP. 2004. 215 f. Dissertação (Mestrado em Geografia) - Universidade Estadual Paulista, Presidente Prudente-SP, 2004.

SÁNCHEZ, Fernanda. A reinvenção das cidades na virada do século: agentes, estratégias e escalas de ação política. Revista de Sociologia e Política, Curitiba, v.16, p. 31-49, jun. 2001.

SANTOS JÚNIOR, J. L. de. A cidade poli(multi)nucleada: a reestruturação do espaço urbano em Salvador. 2008. 402 f. Tese (doutorado em Geografia). Universidade Estadual Paulista, Presidente Prudente, 2008.

SANTOS, M. Manual de Geografia Urbana. 3 ed., São Paulo: EDUSP, 2008a.

A natureza do espaço: técnica e tempo, razão e emoção. 4 ed., São

Paulo: EDUSP, 2008b.

Da totalidade ao lugar. São Paulo: EDUSP, 2008c.

Manual de geografia urbana. São Paul: EDUSP, 2008d.

O espaço dividido: os dois circuitos da economia urbana dos países subdesenvolvidos. 2 ed., São Paulo: EDUSP, 2004.

SILVA, G. C. ; LOPES, W. G. R.; MONTEIRO, M. do S. L.; Presença de condomínios horizontais fechados nas cidades contemporâneas: expansão transformação do espaço urbano. In: Anais do Encontro Latinoamerciano de Edificações e Comunidades Sustentáveis. Curitiba - PR, 21 a 24 de Outubro de 2013. Disponível online em: < http://www.elecs2013.ufpr.br/Anais/comunidades/126-633-1-DR.pdf >. Acesso em 10 de Jun. 2014.

SILVA, S. de S. (Re)produção espacial, intervenções urbanas e a Agenda 2015: a área central de Teresina em questão. 2014. Dissertação (Mestrado em Geografia), Universidade Federal do Piauí: Teresina, 2014.

SPÓSITO, M. E. B. Segregação socioespacial e centralidade urbana. In: VASCONCELOS, P. A. de; CORRÊA, R. L.; PINTAUDI, S. M. (Orgs.). A cidade contemporânea: segregação espacial. São Paulo: Contexto, 2013.

A produção do espaço urbano: escalas, diferenças e desigualdades socioespaciais. In: CARLOS, A. F.; SOUZA, M. de; SPÓSITO, M. E. B. (Orgs.). A produção do espaço urbano: agentes, processos, escalas e desafios. São Paulo: Contexto, 2011.

SPÓSITO, M. E. B.; SOARES, B. R. Agentes econômicos e reestruturação urbana e regional: Tandil e Uberlândia. São Paulo: Expressão Popular, 2010.

. Reestruturação urbana e segregação socioespacial no interior paulista. In:

Revista Scripta Nova. Barcelona: Universidade de Barcelona, vol. XI, no 245 (11), $2007 . \quad$ Disponível em: <file:///C:/Users/Arquivo/Downloads/Reestruturacao\%20urbana\%20e\%20segregacao\% 
20socioespacial\%20no\%20interior\%20paulista_sposito.htm> Acesso em 30 de Setembro de 2014.

- O chão em pedaços: urbanização, economia e cidades no Estado de São Paulo, 2004. 504f. Tese (Livre Docência), Faculdade de Ciências e Tecnologia, Universidade Estadual Paulista, Presidente Prudente, 2004.

. Centralidade intra-urbana. Conjuntura: Prudente. Número especial, p. 4952, Presidente prudente: GASPERR, FCT, UNESP, 2002.

Novas formas comerciais e redefinição da centralidade intra-urbana. In:

SPOSITO, M. E. B. (Org.). Textos e contextos para a leitura de uma cidade média. Presidente Prudente: UNESP, 2001.

Capitalismo e Urbanização. 10 ed., São Paulo: Contexto, 2000.

Reestruturação da cidade. In: MELO, J. L. (org.). Região, Cidade e Poder.

Presidente Prudente-SP: GASPERR, 1996.

TERESINA, P. M. Lei n. 4.423, de 16 de Julho de 2013. Fixa as denominações e delimitações dos bairros de Teresina e dá outras providências. Disponível em: $<$ https://www.leismunicipais.com.br/a/pi/t/teresina/lei-ordinaria/2013/442/4423/leiordinaria-n-4423-2013-fixa-as-denomina-es-e-delimita-os-per-metros-dos-bairros-deteresina-e-d-outras-provid-ncias-2013-07-16.html>. Acesso: 10 jan. 2014.

. Secretaria Municipal de Finanças/Gerência executiva de IPTU. Relatório

de condomínios verticais com número de pavimentos superior a três no cadastro imobiliário fiscal. Teresina: PMT, 2014.

Plano diretor de transportes e mobilidade urbana de Teresina: relatório

final. Teresina, 2008. Disponível em: <http://www.teresina.pi.gov.br/sistemas/portalpmt/admin/upload/documentos/f77f8cb7c a.pdf>. Acesso: 31 ago. 2014.

VAINER, Carlos B. Pátria, empresa e mercadorias: notas sobre a estratégia discursiva do planejamento estratégico. In: ARANTES, Otília; VAINER, Carlos B.; MARICATO, Ermínia. (Org.). A cidade do pensamento único: desmanchando consensos. Petrópolis: Vozes, 2002, p. 75-103.

VIANA, B. A. da S. Caracterização estratigráfica, química e mineralógica do massará e conflitos socioambientais associados a sua exploração em Teresina, PI, Brasil. 2013. 222f. Tese (Doutorado em Geografia), Universidade Federal de Minas Gerais, Belo Horizonte, 2013.

VILLAÇA, F. São Paulo: segregação urbana e desigualdade. Estudos Avançados, São Paulo, v. 25, n. 71, jan./abr. 2011. Disponível em: $<$ http://www.scielo.br/scielo.php?pid= S0103-40142011000100004\&script=sciarttext $>$ Acesso em: 22 nov. 2013.

Espaço intra-urbano no Brasil. São Paulo: Studio Nobel/FAPESP/

Lincol Institute, 2001.

WHITACKER, A. M. Reestruturação urbana e centralidade em São José do Rio Preto. 2003. 238f. Tese (Doutorado em Geografia), Universidade Estadual Paulista, Presidente Prudente, 2003. 